\title{
Correction to: Industrially Important Fungi for Sustainable Development
}

\section{Volume 2: Bioprospecting for Biomolecules}

\author{
Ahmed M. Abdel-Azeem, Ajar Nath Yadav, Neelam Yadav, \\ and Minaxi Sharma
}

\section{Correction to:}

\section{A. M. Abdel-Azeem et al. (eds.), Industrially Important Fungi for Sustainable Development, Fungal Biology, https://doi.org/10.1007/978-3-030-85603-8}

\author{
Owing to an inadvertent error, the book editor Dr. Minaxi Sharma's affiliation in the \\ front matter was presented wrongly as: \\ Minaxi Sharma \\ Chemistry and Biotechnology Department \\ Tallinn University of Technology \\ Tallinn, Estonia \\ The editor's affiliation has now been updated to \\ Minaxi Sharma \\ Senior Research Scientist \\ ERA Chair-VALORTECH \\ Estonian University of Life Sciences \\ Kreutzwaldi 56/5, 51014 Tartu \\ Estonia
}

